\title{
Neuromedin B receptor antagonism inhibits migration, invasion, and epithelial-mesenchymal transition of breast cancer cells
}

\author{
HYUN-JOO PARK ${ }^{1,2}$, MI-KYOUNG KIM ${ }^{1}$, KYU-SIL CHOI ${ }^{3}$, JOO-WON JEONG ${ }^{4}$, \\ SOO-KYUNG BAE ${ }^{2}$, HYUNG JOON KIM ${ }^{1}$ and MOON-KYOUNG BAE ${ }^{1}$
}

\author{
Departments of ${ }^{1}$ Oral Physiology, and ${ }^{2}$ Dental Pharmacology, BK21 PLUS Project, School of Dentistry, \\ Pusan National University, Yangsan 626-870; ${ }^{3}$ Molecular and Cellular Imaging Center, \\ Samsung Biomedical Research Institute, Sungkyunkwan University School of Medicine, Seoul 136-710; \\ ${ }^{4}$ School of Medicine, Kyung Hee University, Seoul 130-701, Republic of Korea
}

Received March 29, 2016; Accepted June 2, 2016

DOI: 10.3892/ijo.2016.3590

\begin{abstract}
Neuromedin B (NMB) acts as an autocrine growth factor and a pro-angiogenic factor. Its receptor, NMB receptor (NMB-R), is overexpressed in solid tumors. In the present study, we showed that an NMB-R antagonist, PD168368, suppresses migration and invasion of the human breast cancer cell line MDA-MB-231. In addition, PD168368 reduced epithelial-mesenchymal transition (EMT) of breast cancer cells by E-cadherin upregulation and vimentin downregulation. Moreover, we found that PD168368 potently inhibits in vivo metastasis of breast cancer. Taken together, these findings suggest that NMB-R antagonism may be an alternative approach to prevent breast cancer metastasis, and targeting NMB-R may provide a novel therapeutic strategy for breast cancer treatment.
\end{abstract}

\section{Introduction}

The bombesin family contains bombesin, a tetradecapeptide originally isolated from amphibian skin, and other mammalian bombesin-like peptides including gastrin-releasing peptide (GRP) and neuromedin B (NMB) $(1,2)$. These peptides play a role a variety of physiological and pathological functions such as smooth muscle contraction, exocrine and endocrine secretion, inflammation, and cancer by activating their respective high-affinity receptors $(3,4)$. These receptors are members of the $\mathrm{G}$ protein-coupled receptor superfamily and play critical roles in tumor development, invasion and metastasis (5). Aberrant expression of bombesin-like peptides and their

Correspondence to: Dr Moon-Kyoung Bae, Department of Oral Physiology, School of Dentistry, Pusan National University, Yangsan 626-770, Republic of Korea

E-mail:mkbae@pusan.ac.kr

Key words: breast cancer cells, epithelial-mesenchymal transition, invasion, metastasis, migration, neuromedin $\mathrm{B}$, neuromedin $\mathrm{B}$ receptor antagonist receptors has been found in some types of human cancers including breast cancers (6).

Accumulating data demonstrates that GRP acts as a mitogen, morphogen and proangiogenic factor in many types of tumors (7-9). Therefore, blocking the GRP receptor by antagonists, monoclonal antibodies, and antisense oligonucleotides have become an attractive therapeutic approach for some types of human tumors $(10,11)$. NMB has been reported to regulate tumor cell proliferation in several cancer cell lines including lung, colon and glioma, and has been shown to trigger intracellular signaling related to tumor cell growth and proliferation through activation of the NMB receptor (NMB-R) (12-14). In line with attempts to investigate the function of NMB/ NMB-R in biological processes, a small non-peptide NMB-R antagonist has been developed and has proven to be useful in understanding the pathophysiology of NMB/NMB-R $(15,16)$. Previously, we have shown that NMB and an NMB-R antagonist can regulate angiogenesis both in vivo and in vitro (17). In addition, we have shown that NMB-R antagonism blocks the growth of breast cancer cells (18). Here, we focused on the inhibitory effect of an NMB-R antagonist on breast cancer cell metastasis. Our results demonstrated that an NMB-R antagonist suppresses migration and invasion capacity as well as EMT of MDA-MB-231 cells, thereby inhibiting breast cancer cell metastasis.

\section{Materials and methods}

Reagents and antibodies. Neuromedin B and PD168368 were purchased from Sigma-Aldrich (St. Louis, MO, USA) and Tocris Bioscience (Minneapolis, MN, USA), respectively. PD168368 was dissolved in dimethyl sulfoxide (DMSO) at a concentration of $5 \mathrm{mM}$ and DMSO was used as a solvent control for all in vitro experiments and in vivo assays involving treatment with PD168368. Antibodies for phospho-mTOR, mTOR, phospho-p70S6K, p70S6K, phospho-AKT, AKT, phospho-GSK3 $\beta$, GSK3 $\beta$, phospho-4EBP1 and 4EBP1 were obtained from Cell Signaling Technology (Danvers, MA, USA). Human NMB-R antibody and $\alpha$-tubulin antibody were obtained from Santa Cruz Biotechnology (Santa Cruz, CA, USA) and BioGenex (Fremont, CA, USA), respectively. 
Cell culture. MDA-MB-231, MDA-MB-468 and MCF-7 cells from the American Type Culture Collection (ATCC; Manassas, VA, USA) were cultured in Dulbecco's modified Eagle's medium (DMEM; Gibco-BRL, Grand Island, NY, USA) containing $10 \%$ heat-inactivated fetal bovine serum (FBS; Gibco-BRL) and $1 \%$ penicillin-streptomycin (Gibco-BRL) at $37^{\circ} \mathrm{C}$ in a humidified atmosphere containing $5 \% \mathrm{CO}_{2}$.

GEO analysis. In order to compare the NMB-R mRNA expression in normal breast tissues and invasive cancer tissues, we analyzed publicly available gene expression datasets of human samples (accession no. GSE10797, http://www.ncbi. nlm.nih.gov/geo/). The differential expression of NMB-R mRNA expression was identified by web-based application GEO2R (http://www.ncbi.nlm.nih.gov/geo/geo2r/) and the Kolmogorov-Smirnov test was used to determine significant differences.

Reverse transcription polymerase chain reaction (RT-PCR) analysis. Total RNA was isolated from MDA-MB-231 cells with a TRIZol reagent kit (Life Technologies, Carlsbad, CA, USA). cDNA synthesis was performed using $2 \mu \mathrm{g}$ of total RNA with a reverse transcription kit (Promega, Madison, WI, USA). The forward and reverse oligonucleotide primers for PCR were as follows: $\beta$-actin, 5'-GACTACCTCATGAAG ATC-3' and 5'-GATCCACATCTGCTGGAA-3'; NMB-R, 5'-CAGAAGTGGCTCGCATCAGT-3' and 5'-GCTGTTGAA ATGCCTCCTGA-3'; E-cadherin, 5'-AACATGGTTCAGAT CAAATC-3' and 5'-AAGCTTGAAGATCGGAGGATTAT CG-3'; vimentin, 5'-TGGCACGTCTTGACCTTGAA-3' and 5'-GGTCATCGTGATGCTGAGAA-3'; Snail, 5'-CTGGGC GCCCTGAACATGCA-3' and 5'-GGCTTCTCCCCCGTGT GAGTTCTA-3'.

Real-time PCR. Real-time PCR quantification was performed using SYBR-Green (LightCycler; Roche Applied Science). Cycling parameters consisted of 1 cycle of $95^{\circ} \mathrm{C}$ for $10 \mathrm{~min}$, followed by amplification for 30 cycles of $95^{\circ} \mathrm{C}$ for $10 \mathrm{sec}$, $57^{\circ} \mathrm{C}$ for $5 \mathrm{sec}$, and $72^{\circ} \mathrm{C}$ for $7 \mathrm{sec}$. Subsequently, a melting curve program was applied with continuous fluorescence measurement. The entire cycling process including data analysis took less than $1 \mathrm{~h}$ and was monitored using the LightCycler software program (version 4.0). The forward and reverse oligonucleotide primers for real-time PCR were designed as follows: $\beta$-actin, 5'-ACTCTTCCAGCCTTCCTTCC-3' and 5'-TGTTGGCGTACAGGTCTTTG-3'; NMB-R, 5'-GGGGT TTCCGTGTTCACTCT-3' and 5'-CAGGAAGATTGTGTGC GCTT-3'.

Western blot analysis. Harvested cells were lysed in a buffer containing $40 \mathrm{mM}$ Tris-HCl, $10 \mathrm{mM}$ EDTA, $120 \mathrm{mM} \mathrm{NaCl}$, $0.1 \%$ Nonidet P-40, and a protease inhibitor cocktail (SigmaAldrich). Samples containing equal amounts of protein (30 $\mu \mathrm{g} /$ lane) were separated by SDS-PAGE and transferred to a nitrocellulose membrane (GE Healthcare Life Sciences, Pittsburgh, PA, USA). The membrane was blocked with 5\% skim milk in PBS or TBS containing $0.1 \%$ Tween-20 for $1 \mathrm{~h}$ at room temperature and probed with the appropriate antibodies. The signal was developed using an enhanced chemiluminescence detection system (GE Healthcare Life Sciences).
Boyden chamber migration assay. Transwell polycarbonate membrane inserts with $8 \mu \mathrm{m}$ pores were coated with $10 \mu \mathrm{g}$ gelatin. MCF-7 or MDA-MB-231 cells were suspended in DMEM at a concentration of $1 \times 10^{5}$ cells $/ 100 \mu 1$, and were added to the upper chamber. NMB $(5 \mu \mathrm{g} / \mathrm{ml})$ or PD168368 $(5 \mu \mathrm{M})$ in DMEM was added into the lower chamber. Migratory MCF-7 or MDA-MB-231 cells appearing on the lower side of the chamber were fixed by careful immersion of the filter into methanol for $1 \mathrm{~min}$, stained with hematoxylin-eosin (H\&E) solution and counted in three random fields per well. Each experiment was performed in duplicate and three separate experiments were performed for each group.

Scratch wound healing assay. Cells were seeded in 6-well plates at a concentration of $1 \times 10^{6}$ cells/well in $1 \mathrm{ml}$ of serum-free DMEM for $6 \mathrm{~h}$, until an adherent monolayer was obtained. A $10 \mu \mathrm{l}$ pipette tip was used to create a scratch in the monolayer and the cells were washed 3 times with serumfree medium. The cells were then placed in fresh serum-free medium and treated with either NMB $(5 \mu \mathrm{g} / \mathrm{ml})$ or PD168368 $(5 \mu \mathrm{M})$. Samples were taken at the beginning and after $24 \mathrm{~h}$ of culture in $5 \% \mathrm{CO}_{2}$ at $37^{\circ} \mathrm{C}$. Images of the scratch wounds were taken and measured by ImageJ software to calculate the mean and standard deviation. Each experimental group was compared with its respective control. The experiments were repeated 3 times.

Invasion assay. Invasion was examined in a Corning Costar Transwell system. The lower and upper sides of polycarbonate filters with $8 \mu \mathrm{m}$ pores were coated with $0.5 \mathrm{mg} / \mathrm{ml}$ type I collagen and $0.5 \mathrm{mg} / \mathrm{ml}$ Matrigel, respectively. The lower compartment contained medium with NMB or PD168368, and MCF-7 or MDA-MB-231 cells were placed in the upper part of the Transwell apparatus. Cell invasion was determined by counting cells on each filter with an optical microscope at $\mathrm{x} 40$ magnification.

Multicellular spheroids/3-dimensional (3D) cell culture assay. MDA-MB-231 cell culture dishes (24-well plates) were precoated with undiluted phenol red-free Matrigel $(10 \mathrm{mg} / \mathrm{ml})$. For each well, $1 \times 10^{4}$ cells were suspended in $200 \mu \mathrm{l}$ PBS and mixed with $100 \mu \mathrm{l}$ of cold Matrigel $(10 \mathrm{mg} / \mathrm{ml})$. The cell suspension was added dropwise over the bottom layer to cover it. After the cell layer was completely set, culture media was added over the top. Media was changed every 2 days without disturbing the cell/matrix layer. Images were taken at the indicated times using x10 magnification for an overview and x40 magnification to document spheroid structure.

Intracardiac experimental metastasis model. Female BALB/c-nude mice (age 8-10 weeks) were anesthetized by intraperitoneal injection of a mixture containing $30 \mathrm{mg} / \mathrm{kg}$ zoletil and $10 \mathrm{mg} / \mathrm{kg}$ xylazine (Rompun). MDA-MB-231 cells ( $2 \times 10^{6}$ cells $/ 0.1 \mathrm{ml}$ in PBS) were injected into the left cardiac ventricle of nude mice with a $26-1 \mathrm{G}$ needle according to previously described methods with modifications (19). Correct injection position in the left ventricle was confirmed by the appearance of bright red blood at the hub of the needle in a pulsatile fashion. The first group of animals received $70 \mu \mathrm{l}$ of vehicle [polyethylene glycol 400 (PEG; Sigma-Aldrich)] by 
intraperitoneal injection, while the second group of animals received $1.2 \mathrm{mg} / \mathrm{kg}$ injections of PD168368 in PEG by intraperitoneal injection. All mice were sacrificed 4 weeks post-tumor inoculation. Any mice showing signs of distress prior to 4 weeks were sacrificed immediately. Animals were euthanized by $\mathrm{CO}_{2}$ asphyxiation and histological analysis was performed. Metastatic lung tissues were prepared and thin sections $(4 \mu \mathrm{m})$ from selected areas were analyzed. After deparaffinization, H\&E staining was used to evaluate morphology. This study conformed to the ethical guidelines of the Institutional Animal Care and Use Committee at Pusan National University, Korea.

Statistical analysis. Data are represented as the mean \pm standard deviation obtained for at least 3 independent experiments. Statistical comparisons between groups were performed by the one-way ANOVA followed by the Student's t-test.

\section{Results}

$N M B-R$ is highly expressed in invasive human breast cancer cells. We analyzed a public genomics data set deposited in the NCBI Gene Expression Omnibus (GEO) database (accession no. GSE10797) in which microarray data were compared between normal breast tissue $(n=5)$ and invasive breast cancer $(n=28)(20)$. This dataset showed a significant increase in NMB-R mRNA expression in invasive breast cancer tissues (Fig. 1A). This result is supported by our previous findings showing NMB-R to be highly expressed in malignant breast tissues $(17,18)$. Based on these results, we explored the expression levels of the NMB-R in 3 human breast cancer cell lines (MDA-MB-231, MCF-7 and MDB-MB-468), by employing RT-PCR, real-time PCR and western blot analysis. As shown in Fig. 1B and 1C, examination of NMB-R gene expression in 3 breast cancer cell lines revealed that NMB-R was expressed in all of these cancer cell lines using RT-PCR and real-time PCR analysis. Moreover, the expression level of the NMB-R mRNA was higher in invasive breast cancer cells (MDA-MB-231) than in less-invasive breast cancer cells (MCF-7 and MDB-MB-468). The pattern in NMB-R expression was confirmed at the protein level in MDA-MB-231 and MCF-7 cells (Fig. 1B, lower). The following studies were designed to investigate the inhibitory role of an NMB-R antagonist in the invasive breast cancer cell line MDA-MB-231 that highly expresses NMB-R.

PD168368 inhibits migration and invasiveness in breast cancer cells. The effect of the NMB-R antagonist PD168368 on cellular behavior of breast cancer cells was determined by migration and invasion assays. Concentrations of PD168369 used in the present study showed no cytotoxic effect on human breast cancer cell lines MDA-MB-231 and MCF-7. We demonstrated that the NMB-R antagonist PD168368 clearly decreased the migratory ability of MDA-MB-231 cells in a Boyden chamber migration assay (Fig. 2A). To complement this Boyden chamber assay, we performed a wound healing migration assay to qualitatively observe the inhibitory effect of PD168368 on the motility of MDA-MB-231 cells. As shown in Fig. 2B, PD168368 treatment decreased the number of cells that migrated into the scratch wound compared to control MDA-MB-231 cells. Next, we examined the effect of PD168368 on invasion capacity of the breast cancer cells in
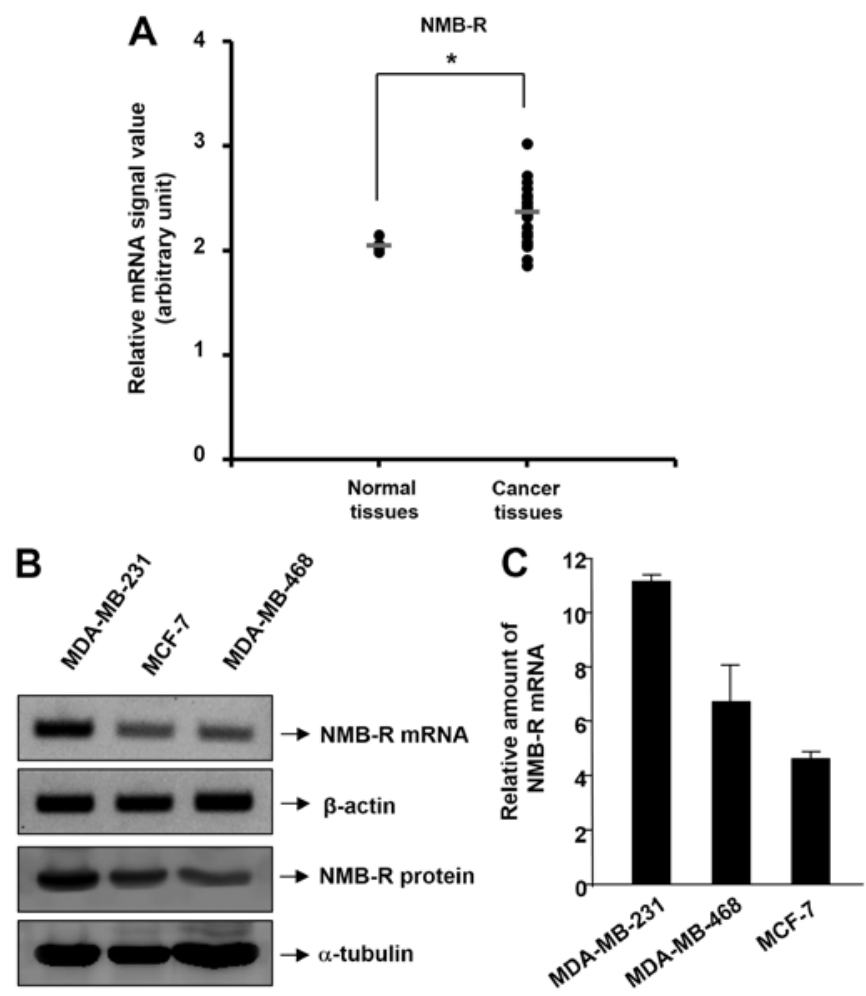

Figure 1. Expression of NMB-R in human breast cancer cell lines. (A) NMB-R mRNA expression levels were analyzed from gene expression dataset GSE10797 deposited in GEO. The difference in mRNA expression between normal and invasive breast cancer tissues was analyzed by a Kolmogorov-Smirnov test ( $\left.{ }^{*} \mathrm{P}<0.01\right)$. (B) The mRNA expression levels of NMBR in MDA-MB-231, MDA-MB-468 and MCF-7 were determined by RT-PCR. $\beta$-actin was used as the internal control (upper). The protein expression levels of NMB-R were examined by western blotting using an anti-NMB-R antibody and $\alpha$-tubulin served as the loading control (lower). (C) Using real-time PCR, the expression level of NMB-R mRNA was quantified from at least 3 independent experiments. The values were normalized to $\beta$-actin mRNA levels.

a Matrigel-based Transwell invasion assay. Treatment with PD168368 suppressed the invasion ability of MDA-MB-231 cells (Fig. 2C). In addition, we investigated the inhibitory effects of PD168368 on NMB-induced migration and invasion of MCF-7 cells by utilizing a Boyden chamber assay. As shown in Fig. 2D, PD168368 inhibited the migration and invasion ability of MCF-7 cells induced by NMB, suggesting that PD168368 specifically inhibited NMB-induced migration and invasion in breast cancer cells.

MDA-MB-231 cells grown in 3D Matrigel culture form thorn or leg shapes, which shows the migratory and invasive properties of these cells (21). However, treatment with PD168368 attenuated these aggressive phenotypes in 3D Matrigel culture (Fig. 2E).

PD168368 regulates EMT in breast cancer cells. The epithelial-mesenchymal transition (EMT) is a crucial early event in the migration, invasion, and metastasis of cancer cells from the primary tumor site $(22,23)$. To investigate whether PD168368 regulates metastatic features of breast cancer cells via inhibiting EMT, we assessed the effect of PD168368 on EMT marker expression in MDA-MB-231 cells by RT-PCR and real-time PCR analysis. As shown in Fig. 3A and B, PD168368 treatment 

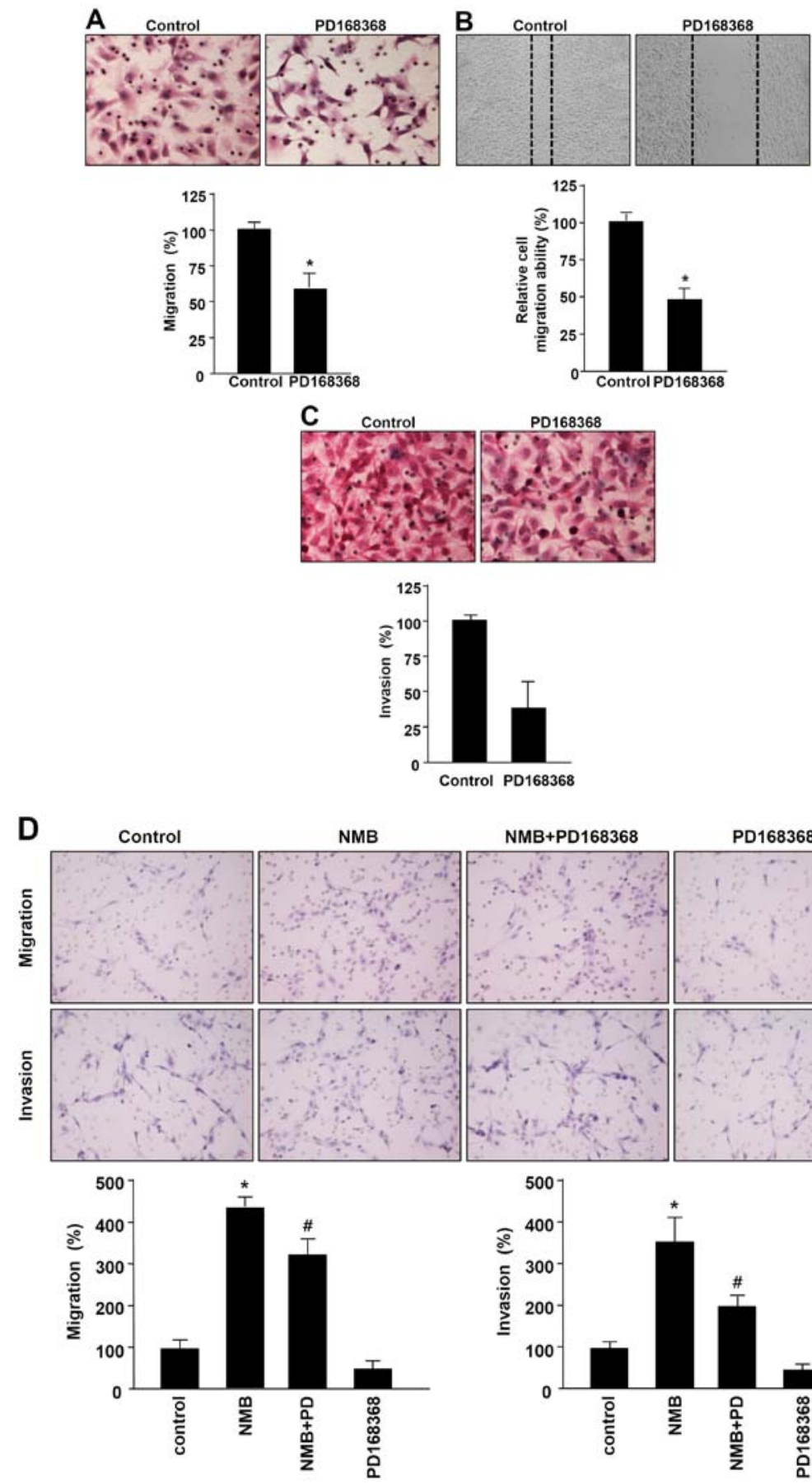

NMB+PD168368

$\mathrm{E}$

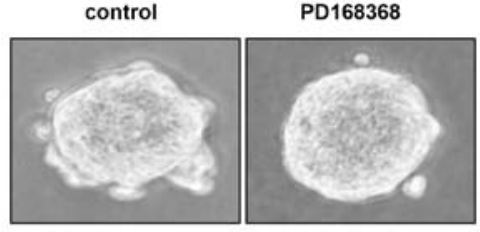

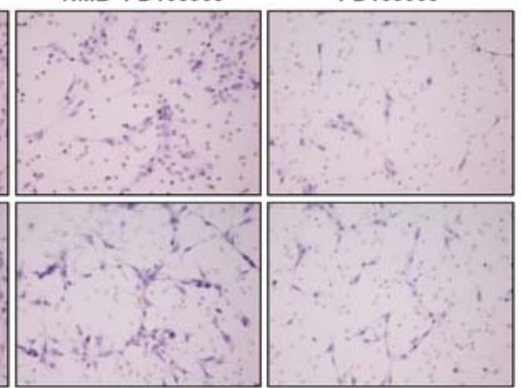
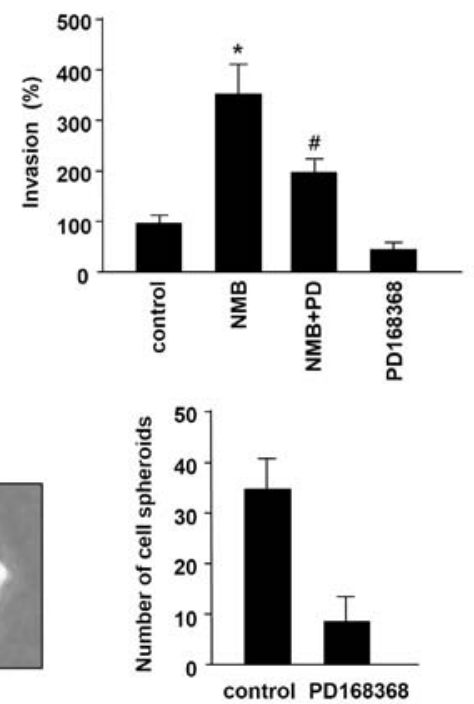

Figure 2. Effect of PD168368 on cell motility and invasiveness of human breast cancer cells. (A) MDA-MB-231 cells were seeded on type I collagen-coated filters for the migration assay. MDA-MB-231 cells in the absence or presence of PD168368 $(5 \mu \mathrm{M})$ were cultured on Transwell chambers for $24 \mathrm{~h}$. The migrated cells were stained with hematoxylin-eosin and photographed (upper). The number of migrated cells was counted (lower). ${ }^{\mathrm{P}}<0.05$ vs. control. (B) The migration capability of the cells were analyzed by scratch wound healing assay. MDA-MB-231 cells treated with PD168368 $(5 \mu \mathrm{M})$ for $24 \mathrm{~h}$ showed significantly altered migration (upper). The number of cells that migrated beyond the reference line was counted (lower). "P<0.05 vs. control. (C) The invasive properties of cells were analyzed by invasion assay using Matrigel-coated Transwell chambers. MDA-MB-231 cells were incubated on Transwell chambers in the absence or presence of PD168368 $(5 \mu \mathrm{M})$ for $24 \mathrm{~h}$. Invasive cells were stained with hematoxylin-eosin and photographed (upper). The number of invaded cells was determined (lower). (D) MCF-7 cells were treated with NMB $(5 \mu \mathrm{g} / \mathrm{ml})$ alone or in combination with PD168368 $(5 \mu \mathrm{M})$, and the invasion and migration abilities of cells were determined (upper). Migrated and invaded cells were stained with hematoxylin-eosin and then counted (lower). ${ }^{\mathrm{P}}<0.05$ vs. control; ${ }^{\mathrm{P}} \mathrm{P}<0.05$ vs. NMB alone. PD, PD168368. (E) MDAMB-231 cells were grown for 7 days in 3D Matrigel cultures in the absence or presence of PD168368 (5 $\mu \mathrm{M})$. Shapes of MDA-MB-231 cells altered with PD168368 treatment were photographed under a microscope (left), and then counted (right). The results shown are representative of at least three independent experiments. 

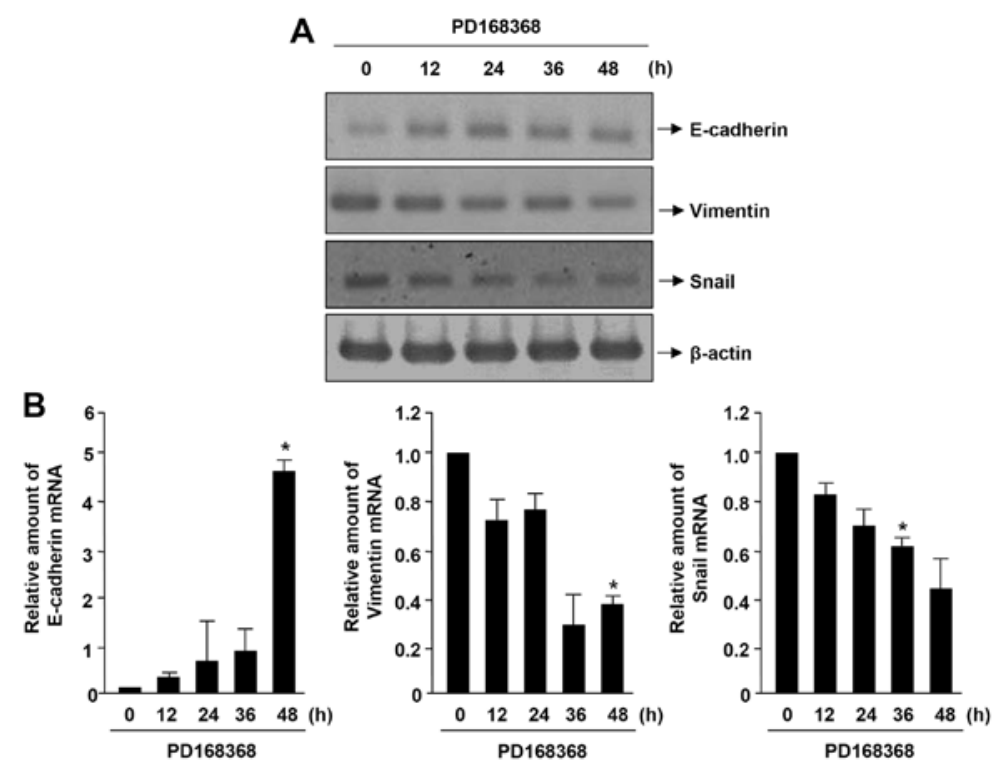

C
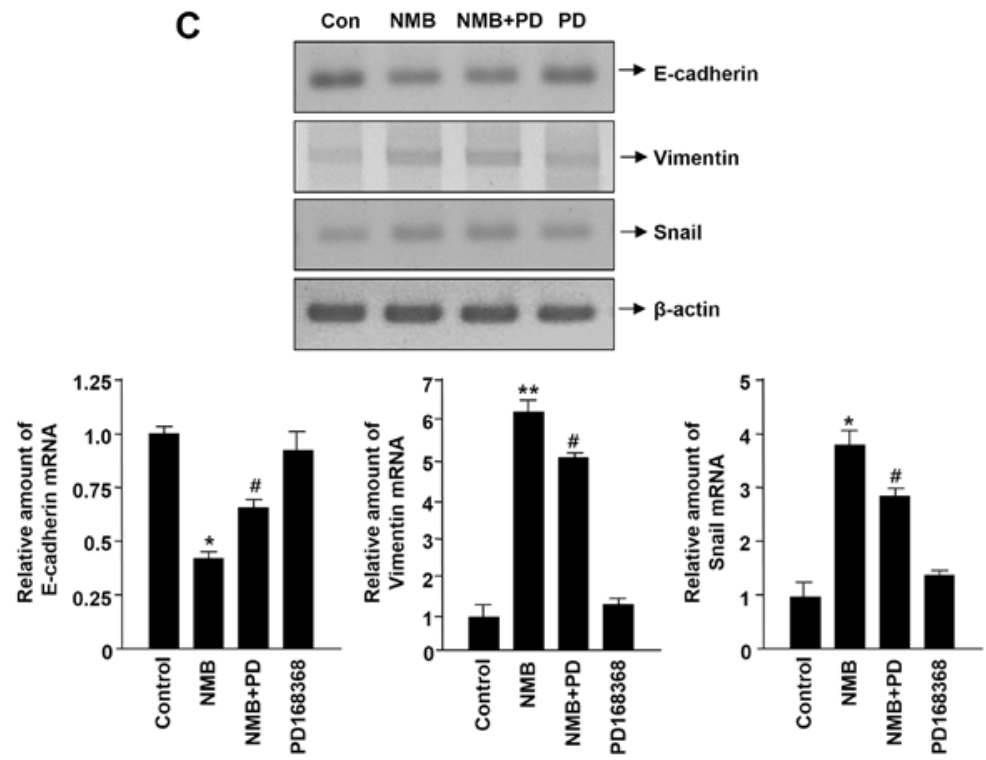

Figure 3. Effect of PD168368 on EMT marker expression in human breast cancer cells. (A and B) MDA-MB-231 cells were treated with PD168368 (10 $\mu$ M) for the indicated times. (A) Total RNA was isolated and then analyzed by RT-PCR using specific primers to human E-cadherin, vimentin and Snail. $\beta$-actin was used as the internal control. (B) Using real-time PCR, the expression levels of E-cadherin, vimentin and Snail mRNA were quantified. The values were normalized to levels of $\beta$-actin mRNA. "P<0.05 vs. control. (C) MCF-7 cells were incubated with NMB (5 $\mu \mathrm{g} / \mathrm{ml})$ in the absence or presence of PD168368 $(10 \mu \mathrm{M})$ for $24 \mathrm{~h}$. Total RNA was isolated and analyzed by RT-PCR using specific primers to human E-cadherin, vimentin and Snail. $\beta$-actin was used as the internal control. The lower panel shows the densitometric analysis of relative E-cadherin, vimentin and Snail expression levels in at least 3 independent experiments. ${ }^{* *} \mathrm{P}<0.01$ vs. control, ${ }^{*} \mathrm{P}<0.05$ vs. control, ${ }^{,} \mathrm{P}<0.05$ vs. NMB alone.

resulted in upregulation of the epithelial marker E-cadherin and downregulation of the mesenchymal markers vimentin and Snail in MDA-MB-231 cells. We next investigated the inhibitory effects of PD168368 on NMB-regulated EMT marker expression in MCF-7 cells by adopting a RT-PCR and real-time PCR assay. As shown in Fig. 3C, PD168368 increased the levels of E-cadherin expression reduced by NMB, whereas PD168368 diminished the levels of vimentin and Snail expression induced by NMB. These results suggest that PD168368 inhibits EMT in breast cancer cells.

PD168368 suppresses the activation of $m T O R / p 70 S 6 K / 4 E B P 1$ and AKT/GSK-3 $\beta$ pathways in breast cancer cells. Recent studies showed that the mTOR pathway is frequently activated in breast cancer metastasis $(24,25)$. Activation of mTOR and the subsequent phosphorylation and activation of its downstream targets p70S6K and eIF4E binding protein 1 (4EBP1) play an important role in promoting cell growth and metastasis in breast cancer $(26,27)$. Therefore, we determined whether NMB stimulates the phosphorylation of mTOR, p70S6K and 4EBP1 in MCF-7 cells. As shown in Fig. 4A, exogenous NMB treatment increased the phosphorylation levels of mTOR, p70S6K and 4EBP1 in MCF-7 cells. Additionally, because activation of the AKT/GSK-3 $\beta$ pathway is emerging as a central feature of EMT $(21,28)$, we speculated NMB regulates AKT/GSK-3 $\beta$ activity in breast cancer cells. Phosphorylation of AKT and GSK-3 $\beta$ were also significantly induced in MCF-7 cells treated with NMB, without obviously influencing total AKT and GSK-3 $\beta$ levels. In contrast, as shown in Fig. 4B, treatment of the MDA-MB-231 cells with PD168368 
A
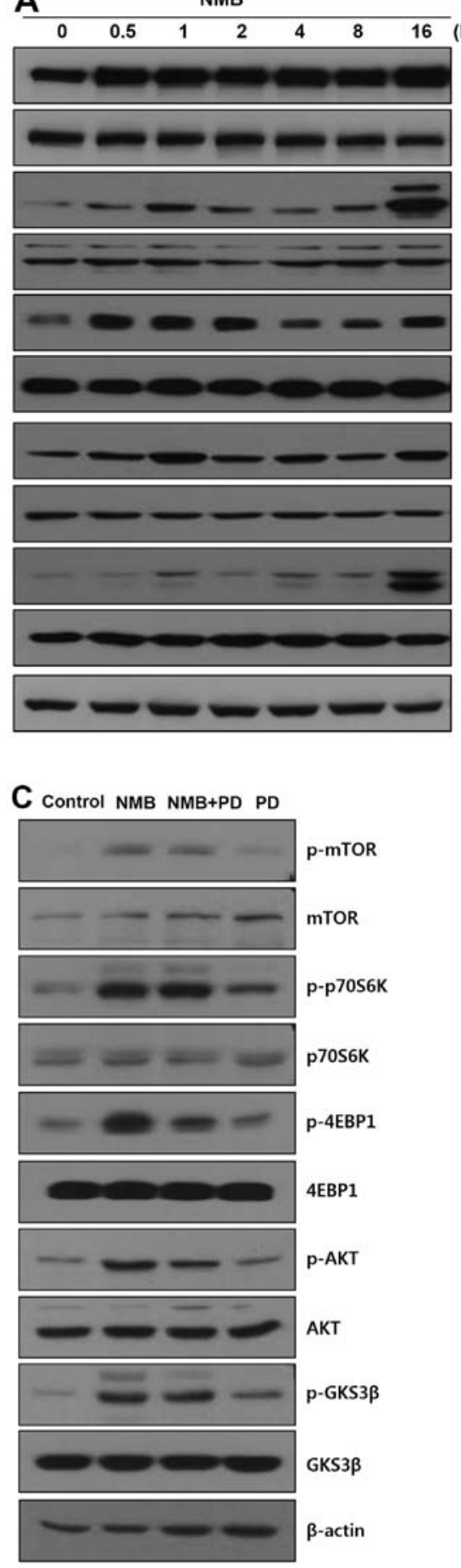

decreased phosphorylation levels of mTOR, p70S6K, 4EBP1, AKT and GSK-3 $\beta$ in a time-dependent manner. Next, we investigated the effect of PD168368 on NMB-induced activation of mTOR/p70S6K/4EBP1 and AKT/GSK-3 $\beta$ in MCF-7 cells. As shown in Fig. 4C, PD168368 effectively reduced the NMB-induced phosphorylation of $\mathrm{mTOR} / \mathrm{p} 70 \mathrm{~S} 6 \mathrm{~K} / 4 \mathrm{EBP}-1$ and AKT/GSK-3 $\beta$ signaling.

PD168368 inhibits metastasis of breast cancer. The effect of PD168368 on breast cancer cell metastasis was further investigated in vivo by employing lung metastasis assays. Cardiac injection of MDA-MB-231 cells $\left(2 \times 10^{6}\right.$ cells/mouse) can lead to the formation of lung metastases in mice. The mice received intraperitoneal injections with PD168368 (1.2 mg/kg) or PEG
B
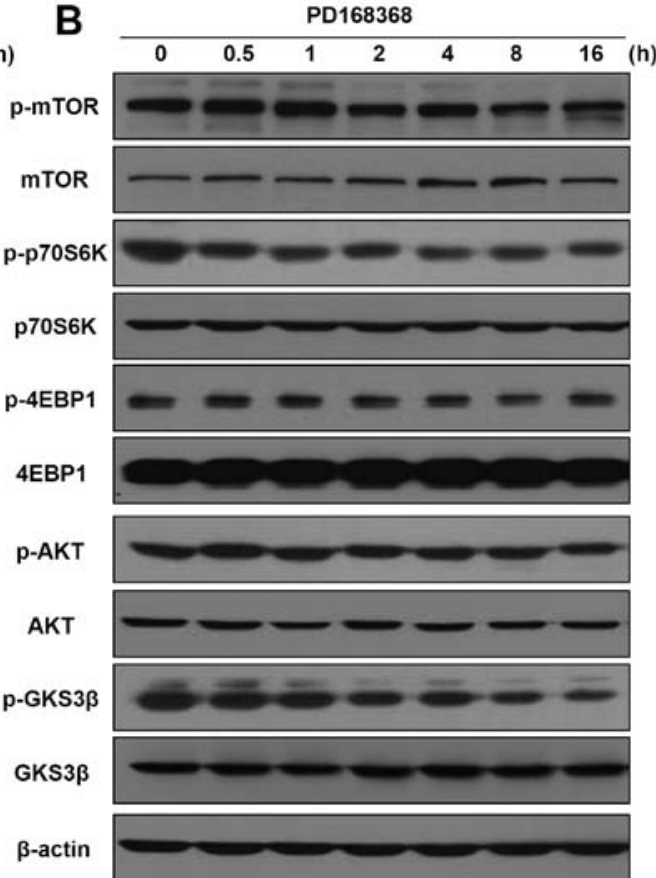

Figure 4. Effect of NMB and PD168368 on mTOR/p70S6K/4EBP1- and AKT/GSK-3 $\beta$ phosphorylation in human breast cancer cells. (A) MCF-7 cells were treated with NMB $(5 \mu \mathrm{g} / \mathrm{ml})$ for the indicated times. Western blots were probed with p-/total-mTOR, p-/total-p70S6K, p-/total-4EBP1, p-/total-AKT and p-/total-GSK-3 $\beta$ antibodies. (B) MDA-MB-231 cells were treated with PD168368 $(10 \mu \mathrm{M})$ for the indicated times. Western blots were probed with p-/total-mTOR, p-/total-p70S6K, p-/total-4EBP1, p-/total-AKT and p-/totalGSK-3 $\beta$ antibodies. (C) The MCF-7 cells were incubated with NMB $(5 \mu \mathrm{g} / \mathrm{ml})$ in the absence or presence of PD168368 $(10 \mu \mathrm{M})$ for $16 \mathrm{~h}$. Western blots were probed with p-/total-mTOR, p-/total-p70S6K, p-/total-4EBP1, p-/total-AKT and $\mathrm{p}$-/total-GSK-3 $\beta$ antibodies. $\beta$-actin served as the loading control. Shown are representative western blots from at least three independent experiments.

(vehicle) for 30 days. As shown in Fig. 5A, no metastatic tumor nodules were observed in lungs of PD168368-treated mice compared to PEG-injected mice. After sacrifice, lungs were collected and sectioned, and H\&E staining showed that the PD168368-injected mice formed much fewer metastatic lung tumors than PEG-injected mice (Fig. 5B and C). These data showed that PD168368 significantly reduces lung metastatic potential of human breast cancer cells.

\section{Discussion}

Bombesin-like peptides and their receptors have been demonstrated to be overexpressed in various types of human malignancies (6). GRP-R is overexpressed in many malignan- 

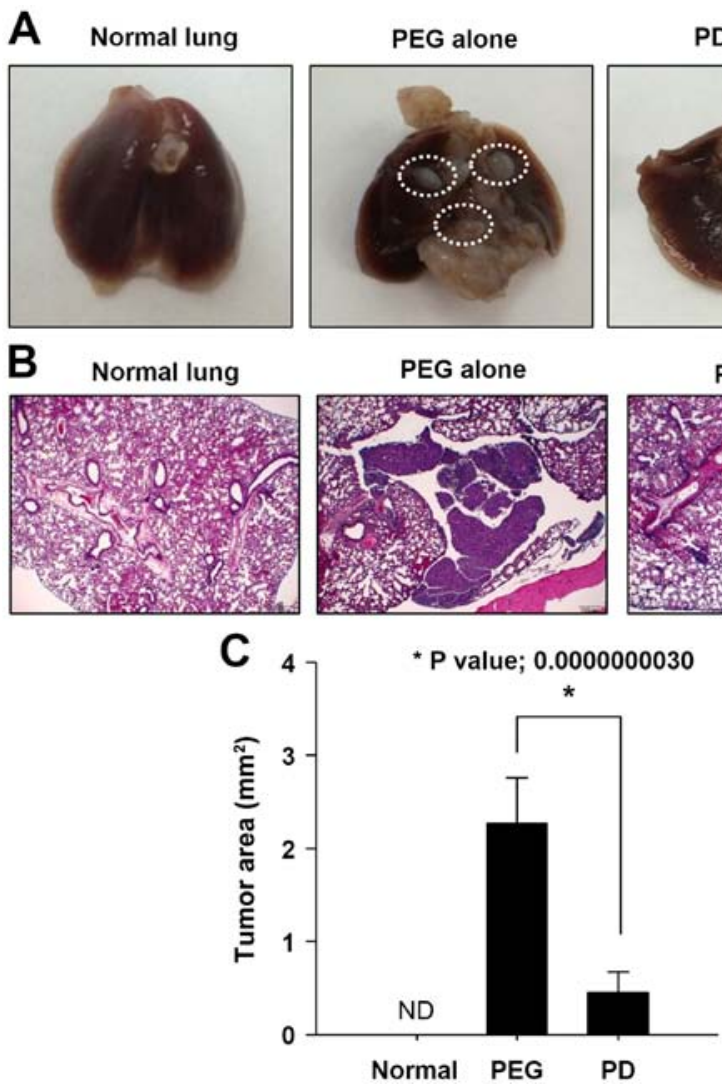

Normal PEG PD
PEG alone

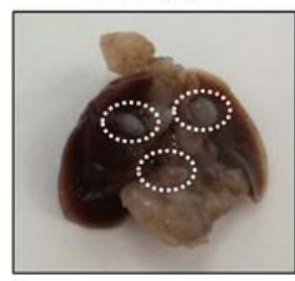

PEG alone
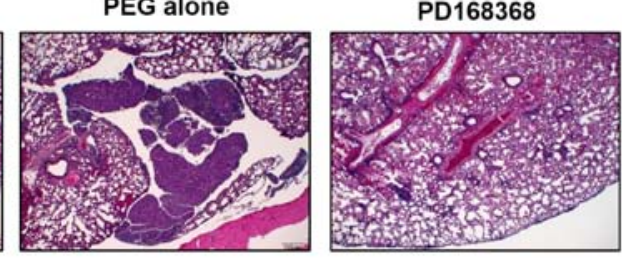

PD168368

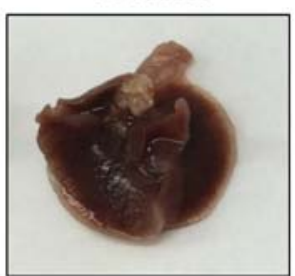

PD168368

Figure 5. Effect of PD168368 on in vivo lung metastasis. (A) MDA-MB-231 cells were injected into the left cardiac ventricle of 8-week-old female athymic nude mice. The first group received vehicle (PEG) treatment by intraperitoneal injection, while the second group of animals received $1.2 \mathrm{mg} / \mathrm{kg}$ injections of PD168368 in PEG by intraperitoneal injection. Normal lungs were used as the negative control. Images of representative animals with metastatic lung nodules are shown from three independent animal experiments. (B) The metastatic lung tissues were removed from mice after 30 days and embedded in paraffin. Tissue sections from metastatic lungs were stained with hematoxylin-eosin and photographed. (C) Histomorphometric analyses were performed from experiments in (B) to quantify the tumor area. The paraffin sections of metastasized lung were prepared and stained with H\&E. The 10 distinct $\mathrm{x} 40$ images from each group were obtained and the tumor area was measured by ImageJ software. The error bars show the mean \pm SD of independent experiments and P-values were based on Student's t-test.

cies including lung (small and non-small cell type), breast, prostate cancer, head and neck squamous cell carcinoma, glioblastoma, pancreatic and ovarian cancer $(7,29)$. Compared to GRP/GRP-R, the role of NMB/NMB-R has received considerably less attention in tumorigenesis, yet, some studies have mentioned NMB-R expression in tumors such as intestinal carcinoids, lung, colon cancer and glioblastoma $(30,31)$. GRP and NMB are often synthesized and secreted from the tumors themselves and both peptides have been shown to exert an autocrine effect on the growth and differentiation of tumors that express GRP-R and NMB-R $(1,32)$. In the present study, we demonstrated that the NMB-R is expressed at a significantly higher level in invasive breast cancer tissues than in non-invasive tissues in dataset GSE10797 deposited in GEO. These results are consistent with those of our previous studies that show expression of NMB-R and NMB in neoplastic breast tissues. Expression of NMB-R (54 of 63 cases, 86\%), (42 of 50 cases, $84 \%$ ), and NMB (41 of 63 cases; $65 \%$ ) were observed in the human breast tumor tissues examined $(17,18)$.

Breast cancer is one of the most commonly diagnosed cancers and is the leading cause of cancer mortality in women (33). The 5-year survival rate for localized breast cancer is relatively high, whereas the survival rate dramatically reduces when breast cancer metastasizes (34). Tumor metas- tasis is driven by a series of biological processes in cancer cells, including acquisition of the ability to migrate from the primary tumor, invade surrounding tissues and metastasize to distal organs (35). To facilitate the early stage of metastatic expansion, malignant cancer cells go through EMT (36). EMT was initially known as a developmental process in which cells lose their epithelial characteristics (including junctions between cells and apical-basolateral polarity) and acquire a mesenchymal phenotype with migratory and invasive properties (37). Lately, the pathological potential of EMT has been applied to the mechanism of tumor invasion and metastasis in several types of cancer, including breast cancer (38). Increasing evidence has shown that malignant breast cancer cells undergo EMT to develop a more motile and invasive phenotype $(39,40)$. Targeting key steps of EMT may serve as an efficient therapeutic strategy for malignant and metastatic breast cancers (41). Here, we investigated the role of PD168368 in the regulation of migration, invasion and EMT in breast cancer cells. We showed that PD168368 regulates the expression of canonical EMT markers, including induction of E-cadherin and loss of vimentin. Snail, a member of the Snail transcription factor superfamily, is known to be a master regulator of EMT by repressing epithelial genes and inducing mesenchymal genes (42). Here, we showed that Snail expression is downregulated 
after treatment with PD168368. Further studies are necessary to investigate whether NMB/NMB-R expression is negatively correlated with the expression of epithelial markers and positively correlated with expression of mesenchymal markers in breast cancer tissues.

The mTOR pathway is frequently activated in breast cancers, and plays a significant role in the growth and metastasis of breast cancer (43). In this study, we demonstrated that NMB activates mTOR and subsequently induces phosphorylation and activation of its downstream targets p70S6K and 4EBP1 in breast cancer cells. In addition, we also found that $\mathrm{NMB}$ induces the activation of AKT in breast cancer cells. The mTOR pathway can be activated by the AKT pathway to induce migratory and invasive properties of breast cancer cells (44), which raises the possibility that NMB activates the mTOR pathway through AKT. Further investigations are required to determine whether NMB drives tumorigenesis and progression to metastasis via the AKT-mTOR signaling pathway in breast cancer.

Collectively, we demonstrated the inhibitory effect of the NMB-R antagonist PD168368 on migration, invasion, and metastasis of human breast cancer cells in vitro and in vivo. Together, our findings suggest antagonism of the NMB-R may be an effective approach for controlling breast tumor metastasis.

\section{Acknowledgements}

This research was supported by a grant from the National R\&D Program for Cancer Control, Ministry of Health \& Welfare, Republic of Korea (1220080), the Basic Science Research Program through the National Research Foundation of Korea (NRF) funded by the Ministry of Science, ICT and Future Planning (2015R1A2A2A01002980) (M-K Bae), and by the 2014 Post-Doc. Development Program of Pusan National University (H-J Park).

\section{References}

1. Majumdar ID and Weber HC: Biology of mammalian bombesinlike peptides and their receptors. Curr Opin Endocrinol Diabetes Obes 18: 68-74, 2011.

2. Erspamer V: Discovery, isolation, and characterization of bombesin-like peptides. Ann NY Acad Sci 547 (1 BombesinLike): 3-9, 1988.

3. Jensen RT, Battey JF, Spindel ER and Benya RV: International Union of Pharmacology. LXVIII. Mammalian bombesin receptors: Nomenclature, distribution, pharmacology, signaling, and functions in normal and disease states. Pharmacol Rev 60 $1-42,2008$.

4. Gonzalez N, Moody TW, Igarashi H, Ito T and Jensen RT: Bombesin-related peptides and their receptors: Recent advances in their role in physiology and disease states. Curr Opin Endocrinol Diabetes Obes 15: 58-64, 2008.

5. Spiegelberg BD and Hamm HE: Roles of G-protein-coupled receptor signaling in cancer biology and gene transcription. Curr Opin Genet Dev 17: 40-44, 2007.

6. Preston SR, Miller GV and Primrose JN: Bombesin-like peptides and cancer. Crit Rev Oncol Hematol 23: 225-238, 1996.

7. Patel O, Shulkes A and Baldwin GS: Gastrin-releasing peptide and cancer. Biochim Biophys Acta 1766: 23-41, 2006.

8. Martínez A, Zudaire E, Julián M, Moody TW and Cuttitta F: Gastrin-releasing peptide (GRP) induces angiogenesis and the specific GRP blocker 77427 inhibits tumor growth in vitro and in vivo. Oncogene 24: 4106-4113, 2005.

9. Jensen JA, Carroll RE and Benya RV: The case for gastrinreleasing peptide acting as a morphogen when it and its receptor are aberrantly expressed in cancer. Peptides 22: 689-699, 2001.
10. Zhou J, Chen J, Mokotoff M and Ball ED: Targeting gastrinreleasing peptide receptors for cancer treatment. Anticancer Drugs 15: 921-927, 2004.

11. Hohla F and Schally AV: Targeting gastrin releasing peptide receptors: New options for the therapy and diagnosis of cancer. Cell Cycle 9: 1738-1741, 2010.

12. Moody TW, Berna MJ, Mantey S, Sancho V, Ridnour L, Wink DA, Chan D, Giaccone G and Jensen RT: Neuromedin B receptors regulate EGF receptor tyrosine phosphorylation in lung cancer cells. Eur J Pharmacol 637: 38-45, 2010.

13. Moody TW, Fagarasan M and Zia F: Neuromedin B stimulates arachidonic acid release, $\mathrm{c}-\mathrm{fos}$ gene expression, and the growth of C6 glioma cells. Peptides 16: 1133-1140, 1995.

14. Matusiak D, Glover S, Nathaniel R, Matkowskyj K, Yang J and Benya RV: Neuromedin B and its receptor are mitogens in both normal and malignant epithelial cells lining the colon. Am J Physiol Gastrointest Liver Physiol 288: G718-G728, 2005.

15. Ryan RR, Katsuno T, Mantey SA, Pradhan TK, Weber HC, Coy DH, Battey JF and Jensen RT: Comparative pharmacology of the nonpeptide neuromedin B receptor antagonist PD 168368. J Pharmacol Exp Ther 290: 1202-1211, 1999.

16. Tokita K, Hocart SJ, Katsuno T, Mantey SA, Coy DH and Jensen RT: Tyrosine 220 in the 5th transmembrane domain of the neuromedin B receptor is critical for the high selectivity of the peptoid antagonist PD168368. J Biol Chem 276: 495-504, 2001.

17. Park HJ, Kim SR, Bae SK, Choi YK, Bae YH, Kim EC, Kim WJ, Jang HO, Yun I, Kim YM, et al: Neuromedin B induces angiogenesis via activation of ERK and Akt in endothelial cells. Exp Cell Res 315: 3359-3369, 2009.

18. Park HJ, Kim SR, Kim MK, Choi KS, Jang HO, Yun I, Bae SK and Bae MK: Neuromedin B receptor antagonist suppresses tumor angiogenesis and tumor growth in vitro and in vivo. Cancer Lett 312: 117-127, 2011.

19. Yin JJ, Selander K, Chirgwin JM, Dallas M, Grubbs BG, Wieser R, Massagué J, Mundy GR and Guise TA: TGF-beta signaling blockade inhibits PTHrP secretion by breast cancer cells and bone metastases development. J Clin Invest 103: 197-206, 1999.

20. Casey T, Bond J, Tighe S, Hunter T, Lintault L, Patel O, Eneman J, Crocker A, White J, Tessitore J, et al: Molecular signatures suggest a major role for stromal cells in development of invasive breast cancer. Breast Cancer Res Treat 114: 47-62, 2009.

21. Liu J, Chen Y, Shuai S, Ding D, Li R and Luo R: TRPM8 promotes aggressiveness of breast cancer cells by regulating EMT via activating AKT/GSK-3 $\beta$ pathway. Tumour Biol 35: 8969-8977, 2014.

22. Chen SC, Kung ML, Hu TH, Chen HY, Wu JC, Kuo HM, Tsai HE, Lin YW, Wen ZH, Liu JK, et al: Hepatoma-derived growth factor regulates breast cancer cell invasion by modulating epithelial-mesenchymal transition. J Pathol 228: 158-169, 2012 .

23. Ning Q, Liu C, Hou L, Meng M, Zhang X, Luo M, Shao S, Zuo X and Zhao X: Vascular endothelial growth factor receptor-1 activation promotes migration and invasion of breast cancer cells through epithelial-mesenchymal transition. PLoS One 8: e65217, 2013.

24. Li X, Yang Q, Yu H, Wu L, Zhao Y, Zhang C, Yue X, Liu Z, Wu H, Haffty BG, et al: LIF promotes tumorigenesis and metastasis of breast cancer through the AKT-mTOR pathway. Oncotarget 5: 788-801, 2014.

25. Lauring J, Park BH and Wolff AC: The phosphoinositide3-kinase-Akt-mTOR pathway as a therapeutic target in breast cancer. J Natl Compr Canc Netw 11: 670-678, 2013.

26. Hay N and Sonenberg N: Upstream and downstream of mTOR. Genes Dev 18: 1926-1945, 2004.

27. Zhou X, Tan M, Stone Hawthorne V, Klos KS, Lan KH, Yang Y, Yang W, Smith TL, Shi D and Yu D: Activation of the Akt/ mammalian target of rapamycin/4E-BP1 pathway by ErbB2 overexpression predicts tumor progression in breast cancers. Clin Cancer Res 10: 6779-6788, 2004.

28. Wang H, Fang R, Wang XF, Zhang F, Chen DY, Zhou B, Wang HS, Cai SH and Du J: Stabilization of Snail through AKT/GSK-3 $\beta$ signaling pathway is required for TNF- $\alpha$-induced epithelial-mesenchymal transition in prostate cancer PC3 cells. Eur J Pharmacol 714: 48-55, 2013.

29. Cornelio DB, Roesler R and Schwartsmann G: Gastrin-releasing peptide receptor as a molecular target in experimental anticancer therapy. Ann Oncol 18: 1457-1466, 2007. 
30. Kuiper P, Verspaget HW, Biemond I, de Jonge-Muller ES, van Eeden S, van Velthuysen ML, Taal BG and Lamers CB: Expression and ligand binding of bombesin receptors in pulmonary and intestinal carcinoids. J Endocrinol Invest 34: 665-670, 2011.

31. Tsuda T, Kusui T and Jensen RT: Neuromedin B receptor activation causes tyrosine phosphorylation of p125FAK by a phospholipase $\mathrm{C}$ independent mechanism which requires p21rho and integrity of the actin cytoskeleton. Biochemistry 36 : 16328-16337, 1997.

32. Ohki-Hamazaki H and Neuromedin B: Neuromedin B. Prog Neurobiol 62: 297-312, 2000.

33. Jemal A, Bray F, Center MM, Ferlay J, Ward E and Forman D: Global cancer statistics. CA Cancer J Clin 61: 69-90, 2011.

34. Weigelt B, Peterse JL and van't Veer LJ: Breast cancer metastasis: Markers and models. Nat Rev Cancer 5: 591-602, 2005.

35. Chaffer CL and Weinberg RA: A perspective on cancer cell metastasis. Science 331: 1559-1564, 2011.

36. Thompson EW, Newgreen DF and Tarin D: Carcinoma invasion and metastasis: A role for epithelial-mesenchymal transition? Cancer Res 65: 5991-5995; discussion 5995, 2005.

37. Thiery JP, Acloque H, Huang RY and Nieto MA: Epithelialmesenchymal transitions in development and disease. Cell 139: 871-890, 2009.

38. Vincent-Salomon A and Thiery JP: Host microenvironment in breast cancer development: Epithelial-mesenchymal transition in breast cancer development. Breast Cancer Res 5: 101-106, 2003.
39. Tomaskovic-Crook E, Thompson EW and Thiery JP: Epithelial to mesenchymal transition and breast cancer. Breast Cancer Res 11: 213, 2009.

40. Wang T, Yuan J, Zhang J, Tian R, Ji W, Zhou Y, Yang Y, Song W, Zhang F and Niu R: Anxa2 binds to STAT3 and promotes epithelial to mesenchymal transition in breast cancer cells. Oncotarget 6: 30975-30992, 2015

41. Kothari AN, Mi Z, Zapf M and Kuo PC: Novel clinical therapeutics targeting the epithelial to mesenchymal transition. Clin Transl Med 3: 35, 2014.

42. Yang F, Zhou X, Miao X, Zhang T, Hang X, Tie R, Liu N, Tian F, Wang F and Yuan J: MAGEC2, an epithelial-mesenchymal transition inducer, is associated with breast cancer metastasis. Breast Cancer Res Treat 145: 23-32, 2014

43. Seeliger H, Guba M, Kleespies A, Jauch KW and Bruns CJ: Role of mTOR in solid tumor systems: A therapeutical target against primary tumor growth, metastases, and angiogenesis. Cancer Metastasis Rev 26: 611-621, 2007.

44. McAuliffe PF, Meric-Bernstam F, Mills GB and GonzalezAngulo AM: Deciphering the role of PI3K/Akt/mTOR pathway in breast cancer biology and pathogenesis. Clin Breast Cancer 10 (Suppl 3): S59-S65, 2010. 